\title{
La teología al servicio del hombre de hoy: conflicto, ciencia y sociedad"
}

\author{
Iván Fernando Mejía Correa*
}

Recibido: 12 de octubre de 2016 Aprobado: 08 de noviembre de 2016.

\section{Resumen}

En el presente artículo se expone cómo la teología puede entrar en diálogo con la comunidad científica y, a la vez, cómo puede abrir horizontes de comprensión nuevos. De otra parte, pretende explicar de qué modo y por qué la teología, al igual que otras ciencias humanas, puede iluminar el 'Proceso de Paz' y el 'pos-conflicto' colombiano.

Palabras Clave: Ciencia, Hermenéutica, Pos-conflicto, Sociedad, Teología.

* Artículo resultado de la investigación doctoral del autor.

* Candidato a doctor en Teología por la Universidad Pontificia Bolivariana e ITEPAL. Magister en Teología (Licenciado canónico en Teología) por la Universidad Pontificia Bolivariana de Medellín, Itepal. Docente de Teología de la Universidad Santo Tomás. Correo electrónico: ivanfernando27@gmail.com 


\title{
Theology at the service of today's man: conflict, science and society
}

\begin{abstract}
This article discusses how theology can enter into dialogue with the scientific community and, at the same time, how it can open new horizons of understanding. On the other hand, it seeks to explain how and why theology, like other human sciences, can enlighten the Colombian 'Peace Process' and 'post-conflict'.
\end{abstract}

Keywords: Science, Hermeneutics, Post-Conflict, Society, Theology.

\section{La théologie au service de l'homme d'aujourd'hui: conflit, science et société}

\section{Résumé}

Cet article expose comment la théologie peut entrer en dialogue avec la communauté scientifique, et comment en même temps elle peut ouvrir de nouveaux horizons de compréhension. D'un autre côté, il prétend expliquer comment et pourquoi la théologie, ainsi que $\mathrm{d}$ 'autres sciences humaines, peut orienter le processus de paix et le post-conflit colombien.

Mots clés: Sciences, Herméneutique, Postconflit, Société, Théologie.

\section{Introducción}

En una sociedad secularizada que permea todas las esferas humanas, es necesaria una reflexión teológica, al tener en cuenta que, como acota Lonergan, la teología es "una mediación entre la religión y la cultura" (Citado por Vélez Caro, 2008, pp. 64-65). Es así que la teología juega un papel preponderante en la sociedad y sirve, además, como 'interlocutora válida' con las ciencias en general y con los ámbitos que afectan a la humanidad, tales como la política, la economía, la sociedad, etc.

Es por eso que en el primer apartado se expondrá, cómo la teología es una necesidad de todo creyente que busca encontrar razón de su existencia, pero no solo buscar razones para los creyentes, sino también para los no creyentes. Hay que recordar que todo cristiano debe explicitar su fe para dar sólidas razones (1 
Pe 3,15) y argumentando cuál es el sentido de esta, y esto se alcanza a través de la teología.

De otra parte, la teología está llamada a dialogar con las ciencias en general. Se hace imperativo, pues, para la teología estar en un diálogo constante con las ciencias, y ello porque puede descubrir otros lugares de comprensión que en muchas ocasiones pasan desapercibidos para otros saberes; en otras palabras, la teología se formula preguntas que la ciencia no considera. Por eso se hace necesario que trate de complementar, desarrollar y analizar el aporte de las ciencias al hombre y a la sociedad de hoy.

De ahí que la teología procede como una hermenéutica que da sentido a ciertas realidades que, de no ser tenidas en cuenta, harían que las ciencias tuvieran una visión reductiva de la realidad, al enfocarse solo en el conocimiento que es posible adquirir por medio del método de las ciencias exactas.

Ahora bien, la teología se hace necesaria en una sociedad que está 'ad portas' de cerrar el conflicto armado, como es la sociedad colombiana que por más de cincuenta años ha estado en pie de guerra. De este modo, la teología tiene que decir algo a una sociedad colombiana que en su génesis tuvo un pasado cristiano, y enseñar a las nuevas generaciones que, a pesar de provenir de hogares cristianos, ya han pasado a un 'pos-cristianismo'.

Sin embargo, la teología se ofrece como esa mediación que busca dar sentido a la existencia humana y, en este orden de ideas, busca sanar las heridas de un pueblo que ha estado sumergido en la violencia por más de una centuria.

\section{La teologia, necesidad del creyente.}

Todo creyente -por el hecho de serlo- está llamado a preguntarse sobre su fe y a dar respuestas. Con palabras de José Morales: “Hay así una teología espontánea, que es aquella comprensión de la fe que tiene todo creyente por el simple hecho de serlo" (Morales, 2008, p. 23). Además de ello, los creyentes están inmersos en la sociedad, que presenta sus problemáticas que no solo los afectan a ellos, sino que también afectan a toda la población. Por ejemplo, el cambio climático es un problema que afecta a todos por igual, pero a diferencia de los no creyentes, el creyente debe iluminar la problemática desde la teología. De hecho, el Papa Francisco ha iluminado la problemática ambiental cuando nos manifiesta:

Si tenemos en cuenta la complejidad de la crisis ecológica y sus múltiples causas, deberíamos reconocer que las soluciones no pueden llegar desde un único modo de interpretar y transformar la realidad. También 
es necesario acudir a las diversas riquezas culturales de los pueblos, al arte y a la poesía, a la vida interior y a la espiritualidad. Si de verdad queremos construir una ecología que nos permita sanar todo lo que hemos destruido, entonces ninguna rama de las ciencias y ninguna forma de sabiduría puede ser dejada de lado; tampoco la teología con su propio lenguaje. Además, la Iglesia Católica está abierta al diálogo con el pensamiento filosófico, y eso le permite producir diversas síntesis entre la fe y la razón. (LS, 63)

El mismo Papa muestra que no se puede absolutizar un solo saber. Es necesario interpretar la realidad desde varias esferas del conocimiento. Cada una aportará una mirada complementaria sobre la realidad. En consecuencia, los creyentes deben asumir la misión de ayudar a complementar la realidad desde otro ámbito como el religioso, que también afecta al mismo hombre. Vicente Vide muestra que no debe haber conflicto entre ciencia y religión, con respecto a lo cual comenta:

Se puede plantear la relación entre la ciencia y la religión de muchas formas. Pero si sólo hay una forma de ver el mundo que pretende dominar o excluir a la otra, entonces se produce un conflicto. [...] O se produce un conflicto o se da una esquizofrenia: cada uno por su lado, y entonces no hay diálogo. Hay quien dice que se complementan, ya que la ciencia nos dice cómo es el cielo, y la religión nos dice cómo se va al Cielo. Pero es mejor ver la ciencia y la religión como dos círculos concéntricos de diferente color, ya que cada una de ellas confiere un tono diferente a la vida; son como dos tipos diferentes de comida, con más o menos sal, con diferentes sabores, con más o menos salsa. Estos círculos son compatibles, al igual que sucede con los aros que hay que encajar en un único pivote. (Vide, 2013, pp. 125-126)

De otra parte, Ángel Cordovilla complementa:

La teología ejercita su connatural función profética leyendo e interpretando la situación espiritual contemporánea. Los fenómenos del ateísmo, la secularización, el misticismo, la violencia sagrada o el pluralismo religioso han vuelto a colocar a Dios en el centro de la vida política y pública. Estos fenómenos que han ido produciéndose en nuestra sociedad o que se dan hoy de forma simultánea requieren una lectura 
y una palabra teológicas que los interprete en la dirección adecuada.

(Cordovilla, 2014, p. 49)

Estos fenómenos descritos por este teólogo necesitan un abordaje teológico, pues presentan una raigambre que en el fondo está cuestionando la relación existente entre Dios y los hombres. Es cierto que estas problemáticas se pueden abordar desde otras perspectivas humanísticas, pero lo que no se puede desconocer es que una lectura teológica ayuda a comprender mejor la problemática y, en esa medida, la mediación teológica se convierte en una nueva mirada que abre a otros horizontes de comprensión. A todas luces, "la teología no puede permanecer indiferente ante esta vuelta de Dios al horizonte humano, ni tampoco ante la aceptación pacífica de su no existencia o su irrelevancia para la vida humana. [...] La teología no sólo tiene la responsabilidad de hablar de Dios, sino además de hablar bien de él". (p. 49)

Hace unos años el connotado teólogo Juan José Tamayo Acosta publicó un libro intitulado "Nuevo paradigma teológico", donde proponía una diversidad de modelos teológicos que ayudaban a realizar una lectura teológica que tenía en cuenta diversos aspectos que, de una u otra manera, afectaban a la teología, pero que a su vez esta estaba en capacidad de responder a dichas realidades. Y fue así como este autor respondía desde la teología a la problemática intercultural, a los problemas suscitados por el fundamentalismo, a las nuevas teologías de género, a la problemática del medio ambiente, y al drama producido por el capitalismo salvaje, etc (Tamayo, 2004).

Para este controvertido teólogo la teología debe mirar otros posibles lugares teológicos, al saber que las problemáticas que trata el autor de una u otra manera contienen elementos que cuestionan los presupuestos religiosos y antropológicos. Es decir, que todo aquello que afecta al hombre también afecta la dimensión religiosa de este. Por ejemplo, el problema económico afecta a todos los hombres y en esa medida -según J. J. Tamayo-

el cristianismo puede contribuir a detener la alocada carrera de la globalización hegemónica, hija del neoliberalismo, hacia la barbarie, activando algunas de las actitudes y opciones ético-proféticas radicales, cuales son: la denuncia de los viejos profetas de Israel contra las estructuras generadoras de pobreza y desigualdad; el anuncio del Reino de Dios como modelo de sociedad y de ser humano nuevos; la incompatibilidad entre Dios y el dinero, la experiencia del compartir, la gratuidad en las relaciones interhumanas, etc. (p. 200) 
Estos son ejemplos que exponen cómo -desde el mundo de la teología- se puede abordar la realidad de una manera seria y profunda. Los teólogos están llamados a disertar sobre las realidades terrenas ${ }^{1}$ (Thil, 1948). Es que "el teólogo se inserta en el seno de una sociedad -la Iglesia-, cuya misión da sentido a su existencia: precisamente transmitir viva la Palabra de Dios a lo largo de la historia, conservando -gracias también a la ayuda divina- la identidad de su fe e iluminando el acontecer humano, histórico y cambiante." (Lorda, 1999, pp. 49-50)

Por ello, los teólogos como creyentes juegan un papel importante en la construcción del mundo, ${ }^{2}$ (Torres Calvo, 1968), por que aportan nuevos horizontes de comprensión que ayudan a tener una mirada más integral del hombre. Eso significa que el discurso teológico asume la función de llamar la atención en aquello que en muchas ocasiones no es tenido en cuenta en otras ciencias, pero que la teología lo aborda desde un horizonte de fe que puede dar explicación y alternativas a las problemáticas humanas.

Por esto que se ha mencionado, la teología se convierte en una voz que puede iluminar las conciencias de la humanidad. Al respecto, Á. Cordovilla acota acertadamente:

La teología es una acción eminentemente social, o dicho de otro modo, toda teología tiene un carácter público [...] Efectivamente, la teología recoge esta tarea humana fundamental y asume así una responsabilidad social ineludible. La teología es la respuesta de la fe pensada ante la revelación pública de Dios, que pide que a su vez sea ejercitada de una forma creyente y pública, en el ámbito de la academia, de la Iglesia y de la sociedad. (Cordovilla, 2014, pp. 35-36)

1 "Reducir a la unidad el dualismo que separa al mundo de Dios; restablecer una armonía nueva y sana entre Cristo y la humanidad; restaurar la unión de la religión con la vida; éste parece ser el significado primero y fundamental de la labor llevada a cabo en nuestros tiempos en busca de una teología de las realidades terrenas" (Thil, 1948, p. 27).

2 “El Verbo de Dios, por quien todo ha sido hecho, que se hizo a sí mismo carne y habitó en la tierra de los hombres, penetró como hombre perfecto en la historia del mundo, tomándola en sí y recapitulándola. Él es quien nos revela "que Dios es caridad" (I Juan, 4,8), y al mismo tiempo nos enseña que la ley fundamental de la perfección humana $y$, por consiguiente, de la transformación del mundo es el mandamiento nuevo del amor. Por consiguiente, a quienes creen en el amor divino les asegura que el camino del amor está abierto para el hombre y que el esfuerzo por restaurar una fraternidad universal no es una utopía. Les amonesta al tiempo que esta caridad no se ha de poner solamente en la realización de grandes cosas, sino, y principalmente, en las circunstancias ordinarias de la vida..." GS, 38,1. (Torres Calvo, 1968, pp. 1271-1272) 
La teología sirve de correctivo, pues, a presupuestos filosóficos y científicos que quieren desvirtuar la trascendencia y acentuar una inmanencia reduccionista. Ya la historia de la humanidad ha experimentado que cuando se coarta la trascendencia, en el fondo se está mutilando la dimensión religiosa de los hombres; pero también cuando una ideología científica no tiene en cuenta los valores humanos, se producen desequilibrios en la manera de entender el fenómeno humano. Además, la teología sirve de correctivo a esos discursos intimistas que no quieren saber nada de la dimensión inmanente de la realidad humana. Por ello, la sana teología quiere corregir esos escollos que se presentan en ciertos discursos teológicos y también en propuestas filosóficas que solo exaltan una sola mirada, al desconocer que ambas -inmanencia y trascendencia- son dimensiones constitutivas del hombre y, por ende, de la realidad (Espeja, 2007).

La teología es esa voz que se alza contra aquellos sistemas totalitarios ${ }^{3}$ (Martínez Real, 2013) que no tienen en cuenta las demandas de la libertad, y también contra aquellas ideologías que desconocen la dignidad de los seres humanos, y se expresan en éticas ${ }^{4}$ (Fernández, 2000) de corte utilitaristas donde los hombres

3 “Probablemente el fenómeno político más importante en el siglo XX haya sido la emergencia del totalitarismo. Los totalitarismos no son reductibles a despotismos, dictaduras o tiranías. Con el totalitarismo apareció una forma completamente nueva de dominación que no se contenta con dominar por medios externos (es decir, a través del Estado y de una maquinaria de violencia), sino que pretende dominar y aterrorizar a los seres humanos desde dentro. El totalitarismo reveló el mal radical al hacer a los hombres superfluos. En nuestros días no hablamos de superfluidad, sino de exclusión. Pero la exclusión es la cualidad por excelencia de nuestro sistema económico en el que los seres humanos no son necesarios; afecta a masas de refugiados e inmigrantes que perdieron su lugar en el mundo y se ven obligados a ir a otros países, donde tampoco tienen lugar; afecta a masas de población de grandes ciudades que ya no necesitan del terror, sino que, seducidas por el señuelo del consumo, se lanzan a sus fauces mortales". Juan Antonio Guerrero-Daniel Izuzquiza. "Vidas que sobran: Los excluidos de un mundo en quiebra (Santander: Sal Terrae, Col. 'Presencia Social', 2003), p. 103. La teología por ejemplo, sale en defensa de aquellos desplazados y denuncia la crueldad del mundo, recordando que todos los hombres deben tener una vida digna. (Martínez Real, 2013, p. 220).

4 "A este respecto, cabe enumerar ciertas escuelas de pensamiento ético que, nacidas casi siempre en ámbitos de la Filosofía, prenden en la confesión protestante, y que, muy pronto, son asumidas por los moralistas católicos. Estas corrientes forman un amplio espectro en el que se sitúan 'modelos' y 'sistemas' distintos, si bien emparentados entre sí. Cabría fijar este orden: en la década de los años cincuenta, surge la 'moral de situación'; le siguen de cerca teorías más extremas en torno a la 'opción fundamental' y a ellas se fusionan las diversas doctrinas cercanas al "utilitarismo", que se presenta como nuevo en contenido y en la nomenclatura, pues se alista en el "teleologismo" ético, entre los que sobresalen el "consecuencialismo" y el "proporcionalismo". (Fernández, 2000, p. 114). En este caso se observa cómo la teología adquiere una labor de crítica a ciertas posiciones éticas que, en primer lugar, afectan la doctrina creyente y también como estas corrientes pierden el sentido de la responsabilidad del hombre ante ciertos actos, y sumen a los 
son tomados como una mercancía más y no como una realidad personal que tiene deberes y derechos.

Indudablemente, la teología, al resaltar que los hombres son creados a imagen y semejanza de Dios (Comisión Teológica Internacional, 2009), revalida la dignidad de las personas, y le dice a la sociedad, a la academia y al mundo secular, que el hombre tiene un puesto principal en el universo, pero para asumir este papel, los hombres se deben dar cuenta de que la realidad humana es pluriforme $\mathrm{y}$, en esa medida, no se pueden desconocer todas las dimensiones que entran en juego en el fenómeno humano. El desconocimiento de esto es lo que ha desencadenado desequilibrios, que se ven reflejados en la misma Naturaleza ${ }^{5}$ (Boff, 2002). Por ello, la teología cumple una dimensión importante en la comunidad creyente, pero a la vez es una voz crítica de toda sociedad que reduce la vida solo a fenómenos que sean productivos y que se puedan manipular, al olvidar que la vida tiene un grado de complejidad mucho más alto.

\section{La teología ante las ciencias.}

Asimismo, no se puede olvidar que la teología jugó un papel preponderante en el nacimiento de la universidad. Es así que "la teología se encuentra en el origen de la universidad medieval y resulta esencial en el desarrollo de ésta" (Cordovilla, 2014, p. 59). Pero, a pesar de ello, cada vez se nota que la teología ha perdido protagonismo en el mundo científico contemporáneo. Con palabras de Á. Cordovilla:

La convivencia pacífica entre la teología y la universidad se va deteriorando con la primacía de las ciencias naturales y experimentales, que poco a poco van imponiendo su método científico al resto de las disciplinas. De este modo, las llamadas 'ciencias del espíritu' (Dilthey)

hombres en un relativismo moral que se expresa en la pérdida de valores (anarquía o anomia axiológico-ética)..

5 “Nuestro planeta Tierra merece un cuidado muy especial. Es el único que tenemos para vivir y habitar. Es un sistema de sistemas y un superorganismo de complejo equilibrio, tejido a lo largo de millones y millones de años. En virtud del asalto depredador del proceso industrial de los últimos siglos, este equilibrio está a punto de romperse en cadena. Desde el principio de la industrialización, en el siglo XVIII, la población mundial ha crecido ocho veces, consumiendo cada vez más recursos naturales; ha crecido más de cien veces. El agravamiento de este cuadro con la mundialización del acelerado proceso productivo incrementa la amenaza y, por consiguiente, la necesidad de un cuidado especial con el futuro de la Tierra". (Boff, 2002, p. 107). 
quedan marginadas, y la creciente secularización de las instituciones estatales y de la sociedad termina por expulsar a la teología de la universidad en algunos países europeos, como Francia y España (no es así en Inglaterra y Alemania). (Cordovilla, 2014, p. 60)

Pero esto, a la postre, ha acarreado un problema en la percepción de la realidad. Las ciencias naturales no son las únicas maneras de conocer la realidad, también hay otras formas de acceder a ella. El inconveniente ha estado en querer leerla desde una perspectiva positivista o cientificista ${ }^{6}$ (Artigas, 2004). De hecho, haber expulsado a la teología de las aulas ha impedido que la realidad pueda ser comprendida desde otros horizontes ${ }^{7}$ (González de Cardedal, 2008).

De igual forma, por ejemplo,

el liberalismo contemporáneo ha asumido y favorecido esa lógica de poner los valores fuera del mundo del conocimiento 'objetivo', al concentrarlos en el coto de la preferencia y la elección subjetiva. El liberalismo no duda de que lo más coherente sea separar los dos ámbitos, público y privado. Y la epistemología moderna, con su adopción del modelo de las ciencias de la Naturaleza y la razón como principio sin referencia y arbitraje más allá de la misma, ha dado carta de ciudadanía a la escisión entre teoría y práctica, hechos y valores, fines e ideales, responsabilidad y convicción. (Martínez, 2011, p. 27)

Aquí se observa como el sistema económico inspirado por el liberalismo -por no tener en cuenta otras lecturas de la realidad-, ha desdeñado la misma

6 "A pesar de sus dificultades y contradicciones, el cientificismo se mantiene y se propaga. Esto significa que, propiamente, se trata de una doctrina que responde a una actitud vital que está más allá de la lógica. Es una concepción global del hombre y del mundo, que pretende ser la visión científica del mundo: éste era el título del manifiesto programático del Circulo de Viena, y esta expresión se repite en obras de tipo cientificista. Es una filosofía y, en cierto modo, una pseudorreligión, pues intenta explicar el sentido de la vida humana y juzgar cualquier otra doctrina. Es, por tanto, una especie de mesianismo que indicaría al hombre cuál es su situación real y cuál ha de ser su actitud básica en el mundo. El problema del cientificismo es que pretende basar sus ambiciosos objetivos sobre la ciencia experimental, y la ciencia no da tanto de sí" (Artigas, 2004, p. 135.)

7 “Aquí en Salamanca, Karl Rahner presentando su curso básico de la fe (Introducción al concepto del cristianismo, 1979), afirmó que una universidad que no tuviera espacio para la teología, arguyendo que su objeto no es verificable, tampoco podría tener espacio para la metafísica, la ética y la estética e incluso para el propio derecho, porque igualmente inverificables son el ser, el deber, la belleza y la justicia. Además, desde el punto de vista positivo, la presencia de Dios en las conciencias ha sido más decisiva para la humanidad que esas realidades". (González de Cardedal, 2008, p. 70). 
realidad. En consecuencia, "la economía tiene necesidad de confrontarse con la instancia moral con el fin de crear un hombre nuevo y un mundo nuevo" (Galindo, 1996, p. 164).

Por tanto, hoy más que nunca debemos escuchar a todas las ciencias y, consecuentemente, también escuchar a la teología, porque abre nuevas perspectivas de comprensión. Es decir, debiera haber un diálogo fluido con la teología y de ella con otras ciencias, saberes y disciplinas. Por ejemplo, "en la actualidad, muchos teólogos piensan que el modo mejor de abordar las relaciones entre ciencia y teología es el diálogo. En este contexto, suele decirse que la ciencia conduce a cuestiones fronterizas que están conectadas con la teología" (Artiga, 2006, pp. 269-270).

Por ello mismo, la teología debe volver a las universidades para entrar en diálogo con otros saberes. Pero, además, “debe ayudar a recordar que lo importante de la universidad son las personas concretas, los hombres de carne y hueso, no la sabiduría en abstracto, ni la ciencia hipostasiada, ni la utilidad funcional de la formación que reciben los estudiantes para el futuro ejercicio profesional" (Cordovilla, 2014, p. 70).

Allí estriba el valor agregado de la teología: mirar la realidad humana no en el plano funcionalista, sino desde una perspectiva creyente. Es decir, el hombre está abierto al plano trascendente ${ }^{8}$ (Morales, 2007). Es una dimensión fundamental de todos los hombres. El problema radica en querer desconocer que el hombre en el fondo es pluridimensional, esto es, no se explica desde una sola perspectiva ni se agota en una mirada. También la teología contiene una posible explicación del fenómeno humano que debe ser tenido en cuenta y no puede ser soslayado arbitrariamente.

Ahora bien, si la universidad es un espacio plural, en esa misma lógica las universidades deben crear espacio para la teología. El encuentro entre varias visiones y horizontes enriquece las temáticas humanas. Por eso,

la universidad tiene que ser realmente 'universitas', es decir, lugar plural y espacio abierto al diálogo con las culturas desde la amplitud de la razón, en cuyo seno debe haber espacio real para la teología en sentido propio y específico, es decir, no sólo como disciplina histórica y

8 "Ser persona significa que el hombre posee una capacidad innata de autotrascendencia, y se halla dotado de una dignidad asociada hondamente a su libertad. [...] La autotrascendencia y el hecho de que el ser humano libre sea señor de su propio destino le permite asombrosamente llegar a ser interlocutor de Dios, como enseña la Biblia y la teología". (Morales, 2007, pp. 87-88). 
cultural, sino incluso como pregunta por la racionalidad de la fe. (Cordovilla, 2014, p. 74)

Es más: la teología puede plantear preguntas que ayuden a mirar los problemas humanos desde otras perspectivas y, por lo tanto, enriquezcan el debate. La teología puede ayudar a que las otras ciencias tengan en cuenta la dignidad de la persona a la hora de realizar experimentos que pueden ir en detrimento de la misma. Un ejemplo de ello es cómo la moral pone en tela de juicio ciertas prácticas que van contra la vida (Sgraccia, 2009).

Asimismo, el diálogo con las otras ciencias ayuda a la teología en cuanto aportan elementos para su reflexión. Con palabras del citado Vicente Vide:

La ciencia aporta a la teología sus conocimientos sobre distintas realidades que constituyen objeto de reflexión teológica, como la vida o la hominización, realidades fundamentales para hablar del pecado o de las cuestiones de bioética sobre el origen y el final de la vida humana. Además, la ciencia ayuda a la teología a reconocer el valor y la autonomía del conocimiento científico. (Vide, 2013, pp. 138-139)

De esto se deduce que debe existir un diálogo entre los distintos saberes humanistas y científicos con la teología, ${ }^{9}$ (Libanio \& Murad, 1996) a partir del cual ambas partes enriquecerán su discurso y el beneficio será para la comunidad humana.

\section{La teología como hermenéutica.}

Sin desconocer que la teología es una ciencia $^{10}$ (Libanio \& Murad, 1996) y sabiduría, ella asume una función hermenéutica (Guibellini, 1993). De hecho, el mismo J. B. Libanio afirma:

9 “La teología está llamada, cada vez más, a articular su saber con las ciencias humanas, al servicio de una reflexión que tenga incidencia, que hable de las realidades terrestres y divinas, en la perspectiva de la fe". (Libanio \& Murad, 1996, p. 347).

10 “La teología se dice ciencia, no en el sentido de tener evidencia inmediata de sus principios, a saber de las verdades reveladas, sino en cuanto ciencia subordinada a la ciencia de Dios. Los principios de la teología sólo se hacen evidentes en la ciencia misma de Dios, es decir, en la ciencia que Dios tiene de sí mismo. La teología de la ciencia de Dios-ciencia subordinante y sus principios. Está en continuidad con la ciencia de Dios, en la que las verdades reveladas participan de la evidencia divina por la Revelación y la fe. Es conocimiento cierto y deductivo, pero a su manera. La teología, como ciencia subalterna se subordina a la ciencia superior de 
La teología siempre ha sido hermenéutica de la fe. Forma parte de su propio concepto e identidad. Reinterpreta y organiza los datos revelados, vividos y comprendidos en y por la comunidad eclesial, en diferentes contextos socio-culturales e históricos. Si no llega a ejercer esta misión, las formulaciones de fe se convierten en anacrónicos y se reducen con el tiempo a pura repetición de fórmulas de poca o insignificante inteligibilidad. (Libanio \& Murad, 1996, p. 324)

Por consiguiente, la tarea del teólogo es tratar de comprender -en primer lugar- el dato revelado, y eso a su vez supone interpretarlo con nuevos lenguajes y métodos para los hombres de una sociedad que tiene otros criterios de vida ${ }^{11}$ (Peukert, 2000). Ahora más que nunca el mensaje revelado necesita una actualización, según la cual se debe explicar al hombre de hoy desde sus categorías, para llevar el mensaje del Evangelio. De ahí que la teología implique una dimensión hermenéutica. Y dicha dimensión interpretativa a su vez debe permear todos los tratados teológicos, pero esto se debe hacer desde una perspectiva cristológica. (Martínez, 2005)

Recordemos, por ejemplo, que los Evangelios son datos de fe. Esa fe debe ser contextualizada e interpretada. La hermenéutica tiene una labor de encarnar el mensaje para el hombre de a pie. De ahí que la Palabra de Dios -y en esa medida todo discurso teológico- debe tocar la existencia ${ }^{12}$ (Guibellini, 1993) concreta del hombre. En este orden de ideas, la teología conlleva una función interpeladora. En consecuencia, la teología está llamada a cuestionar y seguirse formulando preguntas que busquen el sentido de la vida. Toda hermenéutica tiene como cometido buscar sentido, y esto implica comprender qué le dice la propia teología y cómo ayuda a interpretar los datos de la realidad desde otra perspectiva.

Aunque las ciencias humanas incluyen como objeto material al hombre en general, cada una aporta su objeto formal, es decir explica las realidades humanas

Dios y de los santos. Por lo tanto, adquiere más dignidad que las que se fundan en principios conocidos por la luz natural del intelecto evidentes en sí mismas" (pp. 75-76).

11 A este respecto, es necesario tener en cuenta algunas propuestas actuales donde la teología fundamental ha entrado en diálogo con la teoría de la acción comunicativa, lo cual implica utilizar nuevos paradigmas. (Peukert, 2000, pp. 343-352).

12 “Un modo existencial: la iniciativa de Dios en Cristo se actúa en el encuentro concreto, existencial, con la Palabra de Dios, y en la renovación concreta, existentiva, de la existencia y de su autocomprensión. El acontecimiento de la salvación es siempre acontecimiento de la Salvación para mí. Sólo así se puede hablar de Dios en un discurso existencial [...] sin discursos incorrectos y falseadores sobre Dios"' (Gibellini, Op, 1993, p. 44). 
desde una perspectiva particular. La teología -dado su propio objeto formal- interpreta e interpela al hombre y sus realidades desde el Dios de Jesucristo. Pero esto se plasma a través de la Palabra de Dios. Este proceso implica una hermenéutica. El creyente debe interpretar la realidad y lo hace desde la Palabra de Dios. No se trata de imponer lecturas, de lo que se trata es de abrir horizontes. Ese trabajo solo lo hace una hermenéutica bien fundamentada.

Ahora bien, esta hermenéutica debe ser crítico-constructiva ${ }^{13}$ (Libanio \& Murad, 1996, p. 331) y dialogal ${ }^{14}$ (p. 338). Por ejemplo, la teología está llamada a purificar la religiosidad popular ${ }^{15}$ (Benedicto XVI, 2007) y a buscar su sentido e inculturar el Evangelio ${ }^{16}$ (DA, 2007). Pero también la teología debe decir una palabra sobre las víctimas. De hecho, Felicísimo Martínez afirma: “Todos somos responsables de las víctimas, aunque no seamos directamente culpables. Y todos tenemos la obligación de la solidaridad, para dar respuestas efectivas a tanto dolor y tanto sufrimiento. La parábola emblemática del 'Buen Samaritano' vuelve a desafiar a la humanidad" (Martínez, 2005, p. 57).

En consecuencia, la hermenéutica se vuelve necesaria, más aún imprescindible, para cualquier discurso teológico. Porque propone otras alternativas de comprensión, abre horizontes y presenta nuevos marcos referenciales para una lectura de la realidad. La hermenéutica permite una lectura analítica de la realidad a través de la Palabra de Dios.

13 “La tarea crítico-constructiva reúne dos características: como crítica, cuestiona, desinstala y purifica. Y como constructiva, justifica, armoniza e integra. [...] La función constructiva, si está desprovista de la crítica, se hace susceptible de manipulaciones de toda clase, y sirve entonces para consolidar el 'statu quo'" (Libanio \& Murad, 1996, p. 331).

14 “El Concilio Ecuménico Vaticano II reinauguró el diálogo explícito y abierto de la Iglesia con el mundo, rompiendo la larga interrupción que duró como mínimo tres siglos. La teología está llamada al diálogo en toda su amplitud. El diálogo exige algunas condiciones básicas, sin las cuales se producirá solamente un desmotivador monólogo o un 'diálogo de sordos', en el que todos hablan y nadie escucha. Presupone, entre otras cosas, condiciones epistemológicas, lingüísticas, psicológicas, socio-históricas, espirituales y teológicas” (p. 338).

15 "Esta religiosidad se expresa también en la devoción a los santos con sus fiestas patronales, en el amor al Papa y a los demás pastores, en el amor a la Iglesia universal como gran familia de Dios que nunca puede ni debe dejar solos o en la miseria a sus propios hijos. Todo ello forma el gran mosaico de la religiosidad popular que es el precioso tesoro de la Iglesia católica en América Latina, y que ella debe proteger, promover y, en lo que fuera necesario, también purificar". (Benedicto XVI en Aparecida-Brasil, V Conferencia Latinoamericana, 2007).

16 "Con la inculturación de la fe, la Iglesia se enriquece con nuevas expresiones y valores, manifestando y celebrando cada vez mejor el misterio de Cristo, logrando unir más la fe con la vida y contribuyendo así a una catolicidad más plena, no sólo geográfica, sino también cultural" (DA, 2007, N 479). 


\section{La teología en el posconflicto. (Morales Nieto, 2015)17}

El proceso de paz con la guerrilla de las FARC en La Habana (Cuba, hace ya tres largos años) ha permitido que el mundo de la academia haga una lectura del conflicto armado colombiano. Es así que desde todas las disciplinas humanas (política, economía, filosofía, sociología, psicología, historia, etc.) se ofrecen distintas lecturas que ayudan a comprender el conflicto colombiano y el futuro 'proceso de paz'. Sin embargo, así como estas lecturas ofrecen perspectivas valiosas para comprender el conflicto y dar alternativas al proceso de paz, la teología también puede ofrecer una perspectiva valiosa para comprender el conflicto y brindar una alternativa que contribuya a crear una paz estable y duradera.

El pueblo colombiano se dice en su mayoría que tiene una población 'católi$c a^{\prime}$. Sin embargo, en las grandes ciudades se percibe un 'pos-cristianismo'. Pero lo que no se puede olvidar es que Colombia todavía tiene raíces cristianas. En esa medida, la teología debe colaborar con el proceso de paz, ya que tiene elementos suficientes para llegar a ella. En esa medida es elocuente un documento de la Conferencia episcopal de Colombia que aporta unos lineamientos al respecto ${ }^{18}$. Es ahí donde la teología presta un servicio a la Iglesia y también a la sociedad civil. La teología, como se ha visto, desarrolla una hermenéutica que le ayuda a comprender las problemáticas, da horizontes nuevos de interpretación y propuestas para conseguir la paz.

17 Para una mejor comprensión del posconflicto. (Morales Nieto, 2015, p. 196); Revista Javeriana, Marzo de 2016. Número 822, T. 152. Año de publicación 83. ISSN 0120-3088. “La economía de la paz".

18 "Queremos insistir de manera especial en la necesidad de poner por encima de todos los intereses en relación con la problemática de la violencia que hemos vivido, la preocupación por la víctimas. Hay que hacer justicia a todos, a los vivos y a los muertos. Una sociedad que se olvida de las víctimas no tiene futuro y siempre está condenada a repetir estas historias de sufrimiento. Las víctimas tienen un derecho ineludible a la verdad y a la reparación, pero su sanación no puede consistir simplemente en la reparación material. Tiene una importancia muy grande el crecimiento de una sociedad civil que se comprometa con este propósito. Pero es necesaria una formación permanente para la paz: es necesario aprender a convivir pacíficamente, a superar y la tentación de la radicalidad en relación con la solución de los conflictos sociales. Es necesario renunciar a la violencia y desarmar totalmente los corazones. El clima apropiado para realizar esta pedagogía de la paz tiene que estar inspirado por el respeto de la dignidad humana. Hay una conciencia general en el país acerca de la necesidad de participar en el compromiso de trabajar por la construcción de una sociedad más equitativa, por una sociedad capaz de desarrollar condiciones propicias para la convivencia pacífica en un marco ético-político derivado de la puesta en marcha de lo que definimos como el Estado Social de Derecho, con un compromiso incondicional con el respeto de los Derechos Humanos" (n. 92). 
La teología apoyada en la Revelación ${ }^{19}$ (Torres Calvo, 1968) recibe y da elementos para elaborar un proceso de paz. Muestra en principio a los cristianos y a todos los hombres que el mensaje de Jesús está fundamentado en la implementación del Reino de Dios, ${ }^{20}$ (González, 2003) uno de cuyos mayores efectos es la construcción de la paz. Todo el lenguaje evangélico está llamando a los hombres a que despojen el corazón de odios, rencillas, antipatías, en otras palabras, que abran el corazón a Dios que es el que da la paz. De otra parte, "la liberación que Jesús aporta a la historia humana y a la Naturaleza no necesita apelar a la violencia -ni divina ni humana-, ni a los sacrificios, y menos aún a las víctimas" (Tamayo, 2004, p. 161). Es que la propuesta de Jesús se convierte en una lectura paradigmática a la hora de resolver el conflicto colombiano, al saber que muchos de los que participan en el conflicto tienen raíces cristianas. En esa medida, la labor teológica debe ser la de brindar elementos de apoyo, tomados desde la experiencia de Jesús para tratar de construir una nueva sociedad.

De ahí que la teología está llamada a construir la paz. Por ello, las lecturas teológicas también están llamadas a contribuir al nuevo escenario del pos-conflicto. Pero -para este complejo cometido- la teología debe contribuir a destruir las viciosas dinámicas cíclicas de violencia, destrucción, odio, etc. En otras palabras, debe cambiar las dinámicas de violencia por dinámicas de perdón, de reconciliación; de ese modo, la teología está llamada a ser memoria, pues

19 “La Revelación ayuda a conocer mejor las leyes de la vida social. Entre los principales aspectos del mundo moderno se han de contar la multiplicación de las relaciones de los hombres, a cuyo desarrollo contribuye muchísimo el moderno progreso de la técnica. Sin embargo, no es en este progreso donde encuentra su perfección el diálogo fraterno de los hombres, sino más radicalmente en la comunicación de personas, que exige de ellas recíproco respeto hacia una plena dignidad espiritual. Para promover esta comunión entre las personas, la Revelación cristiana aporta una inmensa ayuda y, al mismo tiempo, nos lleva hacia una inteligencia más profunda de las leyes de la vida social, que el Creador dejó grabada en la naturaleza espiritual y moral del hombre" (GS, 23, 1.). (Torres Calvo, 1968, pp. 1725-1726).

20 (González, 2003, p. 414) En este libro, el filósofo-teólogo -compañero del mártir salvadoreño Ignacio Ellacuría- hace un análisis de "Los problemas de la aldea global", que por ende también afectan la problemática colombina; muestra el actual "Sistema económico" y los efectos nefastos que se derivan de la vivencia de un capitalismo salvaje $y$, en contraste de esto, hace una lectura bíblica donde se ofrecen alternativas para buscar el cambio, y por último, plantea el camino para construir una "nueva sociedad"; creo que este estudio es sugerente al observar cómo un teólogo puede leer la realidad apoyado en las ciencias sociales, pero a su vez aplicar una hermenéutica donde ofrece nuevos criterios y alternativas que pueden ayudar a resolver el conflicto colombiano y, de otra parte, muestra cómo la teología puede ofrecer un horizonte nuevo de comprensión que no suprime las otras lecturas, sino que las complementa. Este autor hace un buen ejercicio en que la teología entra en diálogo interdisciplinario con los demás saberes y aporta alternativas liberadoras. 
La memoria implica intentar no repetir el proceso de victimización. La expulsión y su recuerdo conduce por contraste a percibir lo querido por Dios como aquello que edifica la sociedad sin las violencias percibidas por las víctimas. Es decir, una sociedad en la que las víctimas puedan vivir. Una sociedad cuyo sentido de los valores proceda del recuerdo de su victimización. La memoria evoca la base relacional violenta de la sociedad que genera víctimas, convoca a la re-acción a favor de las víctimas y provoca desde la memoria de exclusión y sacrificio un nuevo camino: dejarse mover por el principio-misericordia. (Arango, 2004, p. 71)

Es también ahí donde la teología debe asumir una incisiva perspectiva ecuménica e interreligiosa que obviamente implica inclusión ${ }^{21}$ (Libanio \& Murad, 1996) de otros credos cristianos y religiosos para lograr la consecución de la paz. Todos los credos religiosos están llamados desde sus tradiciones religiosas a fomentar la paz, pero para ello es necesario cultivar una teología dialogante que contenga una perspectiva pluralista y no entre en el callejón del fundamentalismo ${ }^{22}$ (Tamayo, 2006), que en este caso es nefasto para lograr la paz y construir a Colombia en el posconflicto.

De ahí que la teología tiene una función constructiva, reparadora, e interpelante en la construcción de Colombia en el posconflicto.

21 "La teología establece con sus diferentes interlocutores distintos tipos de relación, dependiendo de la materia sobre la cual se entabla la discusión. En el ámbito de la propia Iglesia, la teología dialoga con diferentes grupos de fieles, por medio de movimientos y pastorales, y con el Magisterio en el lenguaje eclesial. En el diálogo con otras Iglesias cristianas, el teólogo fundamenta su contribución en el Evangelio y en la tradición común, llegando a puntos de consenso. En diálogo con las religiones no cristianas, los interlocutores se mueven en el terreno lingüístico de lo 'sagrado' y de la 'experiencia religiosa', a pesar de los términos que esconden significados distintos. Por fin, el diálogo con grupos de la sociedad civil, como científicos, políticos, militantes de movimientos sociales y ecológicos, exige la adopción de otro lenguaje y punto de partida, como la ética". (Libanio \& Murad, 1996, pp. 340-341).

22 "Se puede decir, entonces, que el fundamenalista se caracteriza por miedo al cambio. El cambio se comprende como amenaza de pérdida de referencias fundamentales. La ansiedad que esta amenaza produce lleva al fundamentalista a unirse a grupos que se oponen sistemáticamente a dos temas básicos: el cambio y la interpretación. En el tópico del cambio, el fundamentalista ve el fantasma de la desestructuración interior, y en la interpretación ve un cambio encubierto. Por ello, se debería entender el fundamentalismo como un esfuerzo por superar una angustia vital. Las personas que forman parte de grupos fundamentalistas han pasado por experiencias de aislamiento personal, marginación social, desarraigo, cultural, etc., que les han producido una añoranza de seguridades, de verdades eternas". Voz 'Fundamentalismo' en: Albert Moliner, Nuevo Diccionario de Teología. (Tamayo, 2005, p. 396). 


\section{Referencias}

Arango, Ó. (2004). Teología del principio-Misericordia. Bogotá: Colección ‘Fe y Universidad', Pontificia Universidad Javeriana.

Artigas, M. (2004) Ciencia, Razón y Fe. Navarra: Eunsa. (2006). Filosofía de la ciencia. Navarra: Eunsa.

Boff, L. (2002). El cuidado esencial: Ética de lo humano, compasión por la tierra. Madrid: Trotta.

Comisión Teológica Internacional (2009). Comunión y servicio: La persona humana creada a imagen de Dios: En busca de una ética universal: Nueva perspectiva sobre la ley natural. Madrid: BAC.

Cordovilla, Á. (2014). En defensa de la Teología. Una ciencia entre la razón y el exceso. Salamanca: Sígueme.

Espeja, J. (2007). Encarnación continuada: En la herencia del Vaticano II. Salamanca-Madrid: San Esteban-Edibesa.

Fernández, A. (2000). Ética filosófica y Teología moral: La cuestión del fundamento. Madrid: Ateneo de Teología.

Galindo, Á. (1996). Moral socio-económica. Madrid: BAC.

González, A. (2003). Reinado de Dios e imperio: Ensayo de teología social. Santander: Sal Terrae.

González de Cardedal, O. (2008). El queahacer de la Teología. Salamanca: Sígueme.

Tamayo, J. (2004). Nuevo paradigma teológico. Madrid: Trotta.

Thil, G. (1948). Teología de las realidades terrenas. Buenos Aires: Desclée de Brouwer.

Guibellini, R. (1993). La teología del siglo XX. En: Presencia Teológica. Santander: Sal Terrae.

Libanio, J. \& Murad, A. (1996). Introducción a la Teología. México: Dabar.

Lorda, J. L. (1999). Avanzar en Teología: presupuestos y horizontes del trabajo teológico. Madrid: Palabra.

Martínez, F. (2005). Creer en Jesucristo. Vivir en Cristiano: Cristología y Seguimiento. Navarra: Verbo Divino.

Martínez Real, F. (2013). Economía con Compasión: Variaciones sobre 'Caritas in Veritate'. Salamanca: San Esteban.

Martínez, J. (2011). Moral social y espiritualidad. Una co(i)nspiración necesaria. Maliaño (Cantabria): Sal Terrae.

Morales Nieto, J. (2015). ¿Qué es el Posconflicto? Colombia después de la guerra. En: Revista Javeriana, Marzo de 2016. Bogotá: Ediciones B Colombia. 
Morales, J. (2007). Filosofía de la Religión. Navarra: Eunsa. (2008). Introducción a la teología. Navarra: Eunsa.

Tamayo, J. (edit.) (2005). Nuevo Diccionario de Teología. Madrid: Trota.

Peukert, H. (2000). Teoría de la ciencia y Teología Fundamental. Madrid: Herder.

Sgreccia, E. (2009). Manual de Bioética: Fundamentos y ética biomédica. Madrid: BAC, T. I.

Torres Calvo, Á. (edit.) (1968). Diccionario de los textos conciliares. Madrid: COMPI.

Vélez Caro, O. (2008). El Método Teológico. Fundamentos, especializaciones, enfoques. Bogotá: Pontificia Universidad Javeriana. Facultad de Teología. [Tesis doctoral].

Vide, V. (2013). Comunicar la fe en la sociedad secular. Maliaño (Cantabria) : Sal Terrae. 